10 years ESJ

Special edition

\title{
Mercadotecnia Digital Como Estrategia de Innovación Para el Impulso del Turismo Mexicano en el Contexto de Seguridad Sanitaria
}

\author{
José Leonardo Vázquez Islas \\ Noemi Vega Lugo \\ Universidad Autónoma del Estado de Hidalgo, Mexico \\ Laura Elena Islas Márquez. \\ MALVE Consultoría Educativa, Mexico
}

Doi:10.19044/esj.2021.v17n4p44

Submitted: 28 October 2020

Accepted: 18 December 2020

Published: 07 February 2021
Copyright 2021 Author(s)

Under Creative Commons BY-NC-ND

4.0 OPEN ACCESS

Cite As:

Vázquez Islas J.L., Vega Lugo N. \& Islas Márquez L.E. (2021). Mercadotecnia Digital Como Estrategia de Innovación Para el Impulso del Turismo Mexicano en el Contexto de Seguridad Sanitaria. European Scientific Journal, ESJ, 17(4), 44.

https://doi.org/10.19044/esj.2021.v17n4p44

\section{Resumen}

A partir de diciembre de 2019, inicia en China una enfermedad que nadie imaginó que en poco tiempo afectaría al resto del mundo, con el consiguiente colapso social y económico. En este sentido, para el año 2020, como consecuencia de la emergencia sanitaria, el sector turístico se ha convertido en uno de los escenarios más críticos que requiere una capacidad de reacción en el impulso a las políticas públicas que propicien su resurgimiento, el reforzamiento de la infraestructura de comunicaciones y servicios para consumidores y prestadores de servicio, incremento a los presupuestos para reforzar la promoción de los destinos turísticos, entre otros.Sin embargo, hoy por hoy, el componente más importante en la recuperación del sector turístico mexicano es la Innovación, como estrategia gubernamental y empresarial para el desarrollo y aprovechamiento de tecnología inteligente para la creación de soluciones transformadoras para los retos a los que ya se enfrenta el mercado actual. De esta manera, surge un área de oportunidad muy relevante representada por la Mercadotecnia Digital y el uso de las Redes Sociales, que en alianza estratégica con el Turismo, se constituye como un medio para diseñar un modelo integral 
de gestión para la actividad turística. El presente artículo establece como objetivo identificar las necesidades específicas que presenta el sector turístico y que requieren ser atendidas por la Mercadotecnia Digital como estrategia innovadora mediada por las tecnologías de la información y comunicación, redes sociales y plataformas digitales. Esta investigación de tipo exploratorio, fue diseñada para realizarse de carácter mixto, con enfoque tanto cualitativo como cuantitativo. En su primera etapa muestra los puntos de vista de usuarios frecuentes de las redes sociales en su conocimiento, frecuencia de uso, tipo de canal como rubros que reflejan las necesidades que cubren el criterio de "comunicación efectiva". Ya en el ámbito turístico, se reflejan los intereses específicos sobre la consulta de páginas web, ubicación de servicios, búsqueda de ofertas y diversidad de productos turísticos comercializados por los diferentes proveedores.

Palabras clave: Pandemia, Crisis, Turismo, Mercadotecnia Digital, Innovación

\title{
Digital Marketing as an Innovation Strategy for the Promotion of Mexican Tourism in the Context of Sanitary Security
}

\author{
José Leonardo Vázquez Islas \\ Noemi Vega Lugo \\ Universidad Autónoma del Estado de Hidalgo, Mexico \\ Laura Elena Islas Márquez. \\ MALVE Consultoría Educativa, Mexico
}

\begin{abstract}
As of December 2019, there was a disease outbreak in China that no one imagined would affect the rest of the world within a short time, resulting to the social and economic collapse of many countries. In this sense, by 2020, as a consequence of the health emergency, the tourism sector has become one of the most critical scenarios that need a reaction capacity in promoting public policies that promote its resurgence, the reinforcement of communications infrastructure and services for consumers and service providers, and increased budgets to reinforce the promotion of tourist destinations among others. Today, the most important component in the recovery of the Mexican tourism sector is innovation. Innovation, therefore, is the strategy used by the government and businesses for the development and use of smart technology to create transformative solutions for the challenges it is already facing. Due to the current market, a very relevant area of opportunity arises by using Digital
\end{abstract}


Marketing and Social Networks. In strategic alliance with tourism, it serves as a means of designing a comprehensive management model for tourism activity. This paper focuses on identifying the specific needs presented by the tourism sector and how to meet this needs using digital marketing as an innovative strategy mediated by information and communication technologies, social networks, and digital platforms. This exploratory research was designed to be carried out on a mixed basis, with both qualitative and quantitative approach. In its first stage, it shows the points of view of frequent users of social networks based on its knowledge, frequency of use, and type of channel as items that reflect the needs that cover the criterion of "effective communication". In the tourism field, specific interests are reflected on the consultation of web pages, location of services, search for offers, and diversity of tourism products marketed by different providers.

Keyword: Health crisis, tourism, digital marketing, innovation

\section{Introducción}

A partir de diciembre de 2019, inicia en China una enfermedad que nadie imaginó que en poco tiempo afectaría al resto del mundo, con el consiguiente colapso social y económico. Sistemas de salud y hospitales rebasados en su capacidad, cierre de fronteras y ciudades frenando la movilidad cotidiana, comercios e industria interrumpiendo su actividad, eliminando una gran cantidad de puestos de trabajo, sectores gubernamental, privado y sociedad civil en una crisis a nivel mundial.

De acuerdo a la Organización Mundial de la Salud (OMS) el COVID19 tiene su origen en Wuhan (China) el 31 de diciembre de 2019, siendo una mutación del Síndrome Respiratorio Agudo Severo (SRAS-CoV) presentado en 2003 en Asia y el Síndrome Respiratorio de Oriente Medio (MERSCoV) en 2012 cuyos síntomas son fiebre alta, tos o dificultad para respirar. En casos más graves neumonía, síndrome respiratorio agudo severo, insuficiencia renal y muerte (Salud, 2020).

Derivado de este brote y de sus altos niveles de propagación, el 30 de enero de 2020, la OMS declara emergencia de salud pública de importancia internacional y para el 11 de marzo del mismo año se emite la declaratoria de que el COVID-19 pasa de ser una epidemia a una pandemia.

Al 10 de abril de 2020 se había llegado a una cifra de 1.5 millones de casos confirmados de COVID-19 y más de 92, 000 víctimas mortales en todo el mundo; los países más afectados son China, España, Italia, Alemania y Francia, tomando como primer medida fuertes controles en el ingreso a otros países provenientes de estos destinos con lo que se inicia el caos y la crisis mundial sobre todo el cierre de aeropuertos e inicio de medidas extremas para entrar a un país (Salud, 2020). 
Al 30 de junio de 2020, de acuerdo con cifras emitidas por la Presidencia de la República, la región de las Américas ya es la más afectada con un 56.8\%, Asia Sudoriental con el 13\% ocupa el segundo lugar, con 12.4\% la región de Medio Oriente ésta ocupando el tercer lugar y Europa en un cuarto lugar con el $11.9 \%$ de aportaciones en casos nuevos, en los últimos 14 días (Salud, 2020).

En este contexto tan difícil de entender, afrontar y resolver en el corto, mediano y largo plazo, la actividad turística ha resultado seriamente afectada en todos sus segmentos, ya que el cierre de operaciones se dio a nivel internacional, nacional y local. Es un hecho que el Turismo representa uno de los sectores que de acuerdo a la Organización Mundial de Turismo (OMT) genera ingresos iguales o superiores a las exportaciones del petróleo pues tan solo para el año 2019 en lo que respecta al turismo mundial, cerró con un incremento del $4 \%$ de llegadas de turistas internacionales con respecto a los reportes del año 2018, lo que representa 1.500 millones de llegadas y un gasto aproximado de 5.000 millones de dólares por día, lo que muestra que el sector se ha convertido en uno de los negocios más rentables que el petróleo, productos alimenticios o la industria automotriz.

De acuerdo a los datos arrojados en el último Barómetro OMT del Turismo Mundial, en 2020: Sólo en el primer trimestre, el turismo se ha contraído un $22 \%$, con 67 millones menos de turistas internacionales, lo que traducido en cifras significan 80 mil millones de dólares en pérdidas. Para todo el año, la OMT estima de 850 millones a 1,100 millones menos de llegadas de turistas internacionales, pérdida de 910 mil millones de dólares a 1.2 billones de dólares en ingresos por turismo y de 100 a 120 millones de empleos turísticos directos en riesgo (Conferencia Nacional de Gobernadores \& Consejo Nacional Empresaria Turístico, 2020).

Esta misma fuente expresa que el turismo representa en México más del $8.7 \%$ del PIB, genera más de 4.2 millones de empleos directos, es la tercera parte de divisas cerrando el superávit de la Balanza Turística al 2019 en 14,714 millones de dólares, es el sector que más jóvenes emplea y el segundo en donde trabajan más mujeres. Estas cifras, reflejan el nivel de riesgo y afectación que sufrirá el sector turístico y que se comprobará cuando se cierren las estadísticas anuales de la economía mexicana.

Sin embargo, esta actividad tan importante para el fortalecimiento del país, ha visto afectadas las unidades productivas a lo largo y ancho del territorio, ya que para proporcionar los servicios al turista, las comunidades receptoras cuentan con hoteles, restaurantes, agencias de viajes, transportadoras, líneas aéreas, entre otras, y cada una de ellas a nivel mundial, nacional y local, sufre las consecuencias de esta terrible pandemia, pues han sido obligadas al cierre de actividades y suspensión laboral del personal que presta sus servicios en este sector. 
De esta manera, la situación de la pandemia COVID-19 ha provocado durante el primer trimestre de este año una caída del $22 \%$ en las llegadas de turistas internacionales, previendo que al final del año se pueda alcanzar una disminución de entre 60 y $80 \%$ poniendo en riesgo continuar con el desarrollo de este sector, sin contar por supuesto con la pérdida elevada de empleos y cierre de empresas destinadas a proporcionar servicios turísticos. Otro dato importante es que debido a las restricciones de viaje de enero a abril 2020 las llegadas internacionales disminuyeron en un $44 \%$ con una perdida en dinero de aproximadamente 195,000 millones de dólares en ingresos para el turismo internacional (OMT, 2020).

En el caso de México de acuerdo al estudio realizado por el Consejo Nacional Empresarial Turístico (CNET) y el Centro de Investigación y Competitividad Turístico Anáhuac (CICOTUR), se estima que la reducción para 2020 en el consumo turístico sea de 1.6 millones de pesos lo que equivale al $49.3 \%$ menos que en 2019.

En cuanto al PIB turístico se estima una reducción de $4.9 \%$, prácticamente la mitad de lo alcanzado en 2018 que fue de $8.7 \%$ y se prevé también una perdida aproximada de más de un millón de empleos lo que equivale al $27 \%$.

Se estima en un escenario medianamente optimista, que la recuperación se podrá alcanzar hasta el mes de diciembre con un $55 \%$ en el mercado doméstico y $46 \%$ en el internacional, siempre y cuando se presente ya una solución que disminuya drásticamente con los efectos del virus (vacuna) y se termine el aislamiento social. El escenario pesimista indica que la recuperación se alcanzará en el año 2021.

Por ello, para el año 2020, se confirma que, como consecuencia de la emergencia sanitaria, el sector turístico se ha convertido en uno de los escenarios más críticos en cuanto al impacto negativo de sus aportaciones a las economías locales, nacionales e internacionales y que requiere una capacidad de reacción muy importante de los países y sus estructuras gubernamentales en el impulso a las políticas públicas para el resurgimiento del sector turístico, el reforzamiento de la infraestructura de comunicaciones y servicios para las empresas y usuarios de las empresas turísticas, incremento a los presupuestos para reforzar la promoción de los destinos turísticos, entre otros aspectos que deben ser atendidos fijando estrategias para su reactivación durante y después de la pandemia.

Sin embargo, hoy por hoy, el componente más importante en la recuperación del sector turístico mexicano es la Innovación, como estrategia gubernamental y empresarial para el desarrollo y aprovechamiento de tecnología inteligente para la creación de soluciones transformadoras para los retos a los que ya se enfrenta el mercado actual. De esta manera, surge un área de oportunidad muy relevante representada por la Mercadotecnia Digital y el 
uso de las Redes Sociales, que en alianza estratégica con el Turismo, se constituye como un medio que debe incorporarse en el diseño de un modelo integral de gestión para la actividad turística, involucrando la participación de todos los actores de la sociedad. Es así que, en este escenario de esfuerzos para la recuperación, la Mercadotecnia se redimensiona y toma un papel extraordinariamente destacado en el desarrollo económico, social y cultural, tanto en el plano local como nacional e internacional.

Derivado de lo anterior, destaca la importancia de realizar estudios que permitan visualizar con mayor claridad, el papel tan importante de la Mercadotecnia Digital y su interacción con las tecnologías de información y comunicación (TIC) aplicados al sector turístico, aportando explicaciones teóricas que sustenten y fortalezcan su operación y desarrollo como estrategia de mercadotecnia para la reactivación del turismo ante la seguridad sanitaria que la economía mexicana requiere, posterior a la pandemia del COVID-19.

\section{Metodología}

La presente investigación es de tipo exploratorio, que de acuerdo con Hernández Sampieri, Fernández Collado y Baptista Lucio (2004), se efectúa cuando:

... el objetivo es examinar un tema o problema de investigación poco estudiado, del cual se tienen muchas dudas o no se ha abordado antes. Es decir, cuando la revisión de la literatura reveló que tan sólo hay guías no investigadas e ideas vagamente relacionadas con el problema de estudio, o bien, si deseamos indagar sobre temas y áreas desde nuevas perspectivas o ampliar las existentes.

Así mismo, Arias (2012) define a este tipo de investigación como:

..... aquella que se efectúa sobre un tema u objeto desconocido

o poco estudiado, por lo que sus resultados constituyen una visión aproximada de dicho objeto, es decir, un nivel superficial de conocimientos.

Para Selltiz (1980) la investigación exploratoria es aquella que está:

...dirigida a la formulación más precisa de un problema de investigación, dado que se carece de información suficiente y de conocimiento previo del objeto de estudio, por lo que resulta lógico que la formulación inicial del problema sea imprecisa.

Por otro lado, para la realización de la investigación se consideró el enfoque inicial de Charles Lindbloom sobre los problemas públicos y la orientación de las políticas públicas, con las aportaciones más influyentes de Aaron Wildavsky y Eugene Bardach, quienes insistieron en la importancia del estudio de las redes de implementación de las políticas y ofrecieron evidencia 
suficiente para mostrar la importancia de que una política cuente con un buen diseño y una adecuada planeación en su modo de ejecución. Podestá (2000) precisa que todas sus fases, desde la idea hasta la ejecución, responden a un proceso integral, y Roth (2002) considera que en las políticas públicas, los programas de acción representan la realización concreta de decisiones colectivas; Knoepfel, Larrue, Varone e Hinojosa (2007) identifican que hay una concatenación de decisiones o de acciones, intencionalmente coherentes, tomadas por diferentes actores, públicos y ocasionalmente privados -cuyos recursos, nexos institucionales e intereses varían-a fin de resolver de manera puntual un problema políticamente definido como colectivo. Esto, nos permite construir la base para la búsqueda de la información gubernamental en el impulso a las políticas públicas para el resurgimiento del sector turístico, con lo que se identificarán las necesidades específicas del problema público que requieren ser atendidas por la Mercadotecnia Digital como estrategia innovadora mediada por las tecnologías de la información y comunicación, redes sociales y plataformas digitales.

También se consideró necesario obtener información a través de entrevistas y cuestionarios aplicados a diversos grupos de usuarios de los servicios turísticos, ampliando la comprensión del potencial de las redes sociales y la aceptación general como herramienta de trabajo en la estructura organizacional y operativa ligada con la mercadotecnia turística.

Es así como al abordar el tema de las estrategias en el ramo turístico para la nueva normalidad, lo esencial será familiarizarnos con un tópico poco estudiado o novedoso. Esta clase de investigación sirve para desarrollar métodos a utilizar en estudios más profundos para identificar las estrategias de mercadotecnia que pretende implementar el gobierno mexicano, en trabajo conjunto con los gobiernos de las entidades federativas, mediante el análisis de información arrojada por los órganos de gobierno para hacer frente a la reactivación del turismo en un entorno caracterizado por la llamada nueva normalidad.

\section{Desarrollo}

\section{El COVID-19 y el Turismo.}

\section{Diagnóstico situacional en México y el Estado de Hidalgo}

A inicios del mes de octubre de 2020, durante la comparecencia ante la Comisión de Presupuesto y Cuenta Pública de la Cámara de Diputados del Secretario de Turismo de México, Miguel Torruco Marqués, se planteó un diagnóstico sobre la situación del sector turístico como consecuencia de la pandemia ocasionada por el COVID-19.

Entre otros puntos relevantes se identificó el debilitamiento sufrido por las políticas públicas para mantener el posicionamiento de México país y su sector turístico, agravado en la desaparición del esquema tradicional de 
promoción turística y la necesidad de instrumentar estrategias alternativas, fortalecidas por alianzas estratégicas, racionalidad del uso de recursos públicos y una alta corresponsabilidad con el sector privado.

La problemática del distanciamiento social y cierre de la infraestructura turística detonó en datos negativos, entre los que destacan:

Algunas estimaciones importantes como: reducción de 1.612 billones de pesos en el consumo turístico total, 1.366 billones de pesos en el consumo turístico interno, 245.2 mil millones de pesos en el consumo turístico receptivo (Consejo Nacional Empresarial Turístico \& Centro de Investigación y Competitividad Turística, 2020).

Llevando el conteo de cifras al Estado de Hidalgo, de acuerdo a datos proporcionadas por la Secretaria de Turismo Estatal, durante 2019 arribaron a la entidad 9 millones 851 mil 567 visitantes con una derrama económica de 3 mil 122 millones de pesos, alcanzando el 87\% de ocupación hotelera.

En entrevista realizada al presidente de la Cámara Nacional de Comercio, Servicios y Turismo de Pachuca, capital del Estado de Hidalgo, señaló que de 6 mil empresas existentes en el estado, han cerrado sus puertas temporalmente cinco mil de ellas a partir del 21 de abril que inició de la tercera fase de contingencia sanitaria, perdiéndose aproximadamente 500 millones de pesos en el sector turístico (Reyes, 2020).

Por otra parte en entrevista realizada al Secretario de Turismo del Estado, afirmó que en los primeros 50 días de confinamiento, este sector ha enfrentado una caída del 50\%; también aseveró que pese a la meta planteada para el 2020 de superar los 10 millones de visitantes y turistas que se lograron en 2019, esta cifra podría ser mucho menor afectando seriamente a los prestadores de servicios. Además, se señaló que se perdió la derrama generada en la Semana Santa, faltando festividades y eventos importantes en el estado como la celebración del Día de la Independencia, Día de Muertos, y la Feria Hidalgo 2020 a celebrarse a principios de octubre y en donde la derrama económica proveniente del turismo aumenta considerablemente (Hernandéz, 2020).

Así, la reorientación inicial de las políticas públicas para enfrentar este panorama poco alentador y avanzar en la reactivación del sector con la diversificación de mercados, productos y servicios, requirió de un plan de acción para la contención de la crisis generada por el COVID-19.

Para frenar la propagación de esta enfermedad, el Gobierno Federal (Gobierno de México, 2020) dicta las siguientes medidas preventivas: suspensión de clases en todos los niveles, cierre de áreas públicas como parques, plazas, gimnasios, cines, bares, parcialmente restaurantes y hoteles. También se da a conocer en el mes de marzo el semáforo de riesgo epidemiológico para transitar hacia la nueva normalidad el cual se presenta en cuatro colores que son: 
Rojo. Se permitirán únicamente las actividades económicas esenciales, asimismo se permitirá también que las personas puedan salir a caminar alrededor de sus domicilios durante el día.

Naranja. Además de las actividades económicas esenciales, se permite que las empresas de actividades económicas no esenciales trabajen con el $30 \%$ de su personal, siempre tomando en cuenta las medidas sanitarias, se abren espacios públicos abiertos con un aforo de personas reducido.

Amarillo. Todas las actividades laborales están permitidas, cuidando a las personas con mayor riesgo de presentar COVID-19 dentro de las que se encuentran los adultos mayores, aquellas que presenten enfermedad renal crónica, EPOC, con sistema inmune debilitado, obesidad, afecciones cardiacas graves, con enfermedades de células falciformes y diabéticos, los espacios públicos se abren con regularidad y los espacios públicos cerrados con una afluencia reducida.

Verde. Se permiten todas las actividades, incluidas las escolares.

Cabe mencionar que todas las actividades desarrolladas en cualquiera de los colores de este semáforo se llevarán a cabo con medidas básicas de prevención.

Se contemplan las siguientes medidas que afectan a la actividad turística:

\begin{tabular}{|c|c|c|c|c|}
\hline Restaurantes & $\begin{array}{l}\text { Servicio para } \\
\text { llevar o entrega } \\
\text { a domicilio } \\
\text { No consumo en } \\
\text { el sitio }\end{array}$ & $\begin{array}{l}\text { Alimentos } \\
\text { preparados con } \\
\text { servicio de } \\
\text { consumo en el } \\
\text { sitio al } 30 \% \text { de } \\
\text { capacidad }\end{array}$ & $\begin{array}{l}\text { Alimentos } \\
\text { preparados con } \\
\text { servicio de } \\
\text { consumo en el } \\
\text { sitio al } 50 \% \text { de } \\
\text { capacidad }\end{array}$ & $\begin{array}{l}\text { Alimentos } \\
\text { preparados con } \\
\text { servicio de } \\
\text { consumo en el } \\
\text { sitio al } 70 \% \text { de } \\
\text { capacidad }\end{array}$ \\
\hline $\begin{array}{l}\text { Logística y } \\
\text { servicio de } \\
\text { transporte }\end{array}$ & $\begin{array}{c}\text { Actividad } \\
\text { laboral esencial } \\
\text { con medidas de } \\
\text { protección } \\
\text { personales y } \\
\text { colectivas }\end{array}$ & $\begin{array}{c}\text { Actividad } \\
\text { laboral mínima, } \\
50 \% \text { de } \\
\text { capacidad con } \\
\text { medidas de } \\
\text { protección } \\
\text { personales y } \\
\text { colectivas }\end{array}$ & $\begin{array}{c}\text { Actividad } \\
\text { laboral mínima, } \\
70 \% \text { de } \\
\text { capacidad con } \\
\text { medidas de } \\
\text { protección } \\
\text { personales y } \\
\text { colectivas }\end{array}$ & $\begin{array}{c}\text { Actividad } \\
\text { laboral mínima, } \\
70 \% \text { de } \\
\text { capacidad con } \\
\text { medidas de } \\
\text { protección } \\
\text { personales y } \\
\text { colectivas }\end{array}$ \\
\hline $\begin{array}{c}\text { Servicios de } \\
\text { Hospedaje }\end{array}$ & $\begin{array}{c}\text { Suspensión de } \\
\text { actividades }\end{array}$ & $\begin{array}{c}\text { Actividad } \\
\text { laboral mínima, } \\
30 \% \text { de } \\
\text { capacidad con } \\
\text { medidas de } \\
\text { protección } \\
\text { personales y } \\
\text { colectivas }\end{array}$ & $\begin{array}{c}\text { Actividad } \\
\text { laboral mínima, } \\
50 \% \text { de } \\
\text { capacidad con } \\
\text { medidas de } \\
\text { protección } \\
\text { personales y } \\
\text { colectivas }\end{array}$ & $\begin{array}{c}\text { Actividad } \\
\text { laboral mínima, } \\
70 \% \text { de } \\
\text { capacidad con } \\
\text { medidas de } \\
\text { protección } \\
\text { personales y } \\
\text { colectivas }\end{array}$ \\
\hline
\end{tabular}

Adicionalmente, se publica como estrategia la reducción de la movilidad pública de un 35 a 40\%, en el estado mediante el programa Hoy no Circula, además de limitar la circulación a un máximo de dos personas por vehículo (Reyes, 2020). 
En Pachuca (capital del estado de Hidalgo) se han afectado: los recorridos turísticos, módulos de información, cierre de museos, el principal atractivo turístico denominado Reloj Monumental y la oficina de Turismo Municipal sólo proporciona información vía telefónica y recorridos virtuales.

$\mathrm{Al}$ inicio de esta contingencia los hoteles bajan drásticamente a una capacidad menor al 50\% de ocupación, los restaurantes ofrecen comida para llevar y servicio a la mesa con medidas sanitarias al 50\%. Lo anterior deja un panorama económico desalentador ante la contingencia que se extenderá hasta un tiempo no definido, según declaraciones del gobierno federal. Por su parte, el gobierno hidalguense ha emitido medidas y acciones en apoyo a la economía, directamente al sector turismo de servicios, donde se exime en un $100 \%$ el impuesto por la prestación de servicios de hospedaje en el periodo marzo-abril, apoyo en créditos y 50\% del pago del impuesto sobre nómina para pequeñas y medianas empresas (UNOTV,2020).

Como se puede visualizar, las medidas drásticas tomadas a nivel mundial para frenar esta pandemia han afectado directamente a la actividad turística, llevando a redimensionar el actuar de muchos de los empresarios dedicados a este negocio, apoyados el replanteamiento de la política pública para el fortalecimiento de productos y servicios turísticos a través de la implementación de un programa de Mercadotecnia Turística con alcance a las principales estrategias: Pueblos Mágicos, Consejo de Diplomacia, Ferias Internacionales y Operación Toca Puertas, Visit México y la Comercialización de Productos y Servicios y Tianguis Turístico.

Para ejemplificar lo anterior, es preciso señalar la atribución que tiene el Estado Mexicano para planear, conducir, coordinar y orientar la actividad económica, así como la regulación y fomento de las actividades que demande el interés general, precisando la participación con responsabilidad social del sector público, el sector social y el sector privado. En este contexto, los Objetivos y Líneas Estratégicas plasmados en el Acuerdo por el que se expide la Estrategia Nacional de Pueblos Mágicos (DOF, 2020), como guía para el desarrollo de una nueva visión del turismo en los Pueblos Mágicos, son los siguientes:

\begin{tabular}{|c|c|}
\hline Objetivos & Líneas Estratégicas \\
\hline $\begin{array}{l}\text { 1.-Impulsar un enfoque social y } \\
\text { de respeto a los derechos } \\
\text { humanos en la } \\
\text { actividad turística, para el } \\
\text { bienestar de las personas que } \\
\text { viven y trabajan en los Pueblos } \\
\text { Mágicos. }\end{array}$ & $\begin{array}{c}\text { a. Desarrollar políticas públicas que contribuyan al } \\
\text { turismo con enfoque social e incluyente. } \\
\text { b. Impulsar el turismo accesible para contribuir al } \\
\text { bienestar de la población vulnerable. } \\
\text { c. Fomentar la coordinación intersectorial para el } \\
\text { bienestar de los Pueblos Mágicos. } \\
\text { d. Promover la coordinación con los sectores público } \\
\text { y social en materia de seguridad y } \\
\text { protección integral al turista para mejorar la } \\
\text { confianza de los visitantes en los Pueblos } \\
\text { Mágicos. }\end{array}$ \\
\hline
\end{tabular}




\begin{tabular}{|c|c|}
\hline $\begin{array}{l}\text { 2.- Fomentar el desarrollo justo } \\
\text { y equilibrado entre los } \\
\text { individuos, comunidades } \\
\text { y regiones para democratizar los } \\
\text { beneficios del turismo en las } \\
\text { comunidades receptoras. }\end{array}$ & 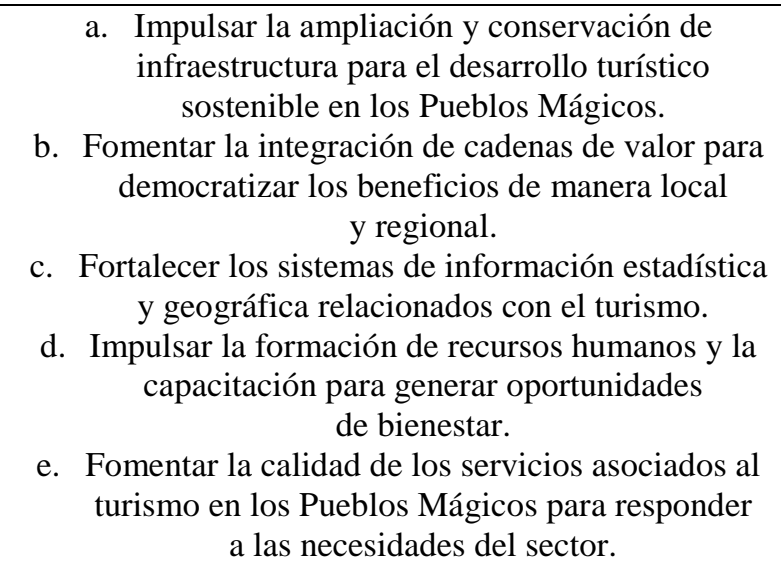 \\
\hline $\begin{array}{l}\text { 3.- Fortalecer la innovación y } \\
\text { diversificar las oportunidades de } \\
\text { comercialización de la oferta } \\
\text { turística de los Pueblos Mágicos }\end{array}$ & $\begin{array}{l}\text { a. Impulsar el uso de tecnologías de la información } \\
\text { para elevar el potencial turístico de los } \\
\text { Pueblos Mágicos. } \\
\text { b. Fomentar la innovación en la promoción y } \\
\text { comercialización para incrementar los flujos } \\
\text { turísticos y la inversión hacia los Pueblos Mágicos. } \\
\text { c. Promover la diversificación de mercados para } \\
\text { posicionar a los Pueblos Mágicos en la preferencia } \\
\text { del turismo nacional e internacional. }\end{array}$ \\
\hline $\begin{array}{l}\text { 4. Fortalecer la innovación y } \\
\text { diversificar las oportunidades de } \\
\text { comercialización de la oferta } \\
\text { turística de los Pueblos Mágicos }\end{array}$ & $\begin{array}{l}\text { a. Contribuir a la mitigación de las externalidades del } \\
\text { turismo para generar bienestar y } \\
\text { desarrollo sostenible. }\end{array}$ \\
\hline
\end{tabular}

Construcción propia a partir del Diario Oficial de la Federación de fecha $1^{\circ}$ de octubre de 2020

Es preciso hacer hincapié que el objetivo 3 establece el propósito de "fortalecer la innovación y diversificar las oportunidades de comercialización de la oferta turística de los Pueblos Mágicos", lo que abre las oportunidades de innovación y desarrollo para implementar el uso de tecnologías de información en la promoción y comercialización de productos y servicios turísticos. 


\section{Estrategias y Prospectiva de la Mercadotecnia Digital}

Entre los principales componentes para la comprensión de las necesidades para la reactivación de la industria turística a través de la innovación en la promoción y comercialización, se recuperan los aportes de Kotler y Armstrong (2003), donde el contexto inicial precisa las características identificadas en la Mercadotecnia Turística, como son: intangibilidad, inseparabilidad, variabilidad y perecibilidad. En este marco, se establece una relación con el tipo de productos y servicios, acorde a sus propiedades, a saber: Bien tangible puro; Bien tangible con servicios acompañantes; Bienes/servicios con oferta híbrida; Servicio con bienes acompañantes menores; y, Servicio puro. Así, se identifica que existen servicios turísticos que se ubican en la oferta híbrida, donde se encuentran las empresas y/o instituciones que ofrecen productos alimenticios, vinculados con el servicio de hospedaje, así como las empresas de transportación turística que se ubican en el tipo de servicio con bienes acompañantes menores.

Conforme pasan los años, ya no se habla sólo de los productos y empresas turísticas. Sus características y la forma de relacionarse van cambiando vertiginosamente y ahora la industria turística es reconocida por entrar a la categoría de fenómeno multifactorial. Los avances y retos para el desarrollo, comercialización y promoción del sector turístico se identifican por su complejidad. De acuerdo con Barroso (2010),

"en el contexto mundial de competitividad en que se encuentran los países, definidos como productos de la actividad turística, mantener una diferenciación se torna muy difícil, especialmente si se tiene en cuenta la comoditización (oferta de productos y servicios idénticos) existente en la actividad. En general las empresas, productos y países buscan proyectar la mejor imagen de sí mismos teniendo en cuenta sus diferencias competitivas; y para esto consideran las inversiones, el desarrollo local, las oportunidades de negocios, además del clima, la geografía, las costumbres, los valores y la cultura".

Aunado a esto, el entorno también ha cambiado, puesto que su análisis ya no puede prescindir de la estructura de capital intelectual y sus componentes del capital humano aportando conocimiento, capital estructural con sus prácticas, técnicas y metodologías, capital relacional representado por la red de personas, empresas, instituciones y colectivos trabajando en torno a un tema, así como con el capital organizacional que representa la inteligencia cohesionada por la gestión de las grandes cantidades de datos.

Surgen así los ecosistemas que ahora se distinguen por adoptar la multiplicidad de redes a través del modelo de la "Penta Hélice" que Arechavala (2020) identifica con el estudio de los retos y problemas de un país, con la participación del gobierno, empresas, academia, sociedad y el medio ambiente, en un esquema de colaboración conjunta que integra al 
entorno, componente fundamental para la innovación y desarrollo de las actividades turísticas.

De forma creciente, la tecnología ha ido permeando en las actividades turísticas con el propósito de incidir en la competitividad de los servicios y destinos, aunque enfrentando retos y áreas de oportunidad que las empresas y la población en general enfrenta y que son difíciles de resolver y que obligan a un análisis minucioso para el diseño de innovaciones tecnológicas para el turismo, planteados por Espino y Pérez-Nazar (2020) como elementos imprescindibles para dar el siguiente paso hacia nuevos escenarios:

- Inexistente desarrollo de habilidades y capacidades tecnológicas en las micro, pequeñas y medianas empresas.

- Identificación de datos estratégicos.

- Selección de información cualitativa y cuantitativa.

- Capacidad de absorción del conocimiento.

- Capacidad de análisis e interpretación de información.

- Involucramiento del sector público y privado en proyectos y acciones conjuntas para motivar el uso de las plataformas y soluciones digitales dirigidas al ecosistema turístico de México.

En el centro de estos debates, se encuentra el surgimiento y avance que han tenido las redes sociales aplicadas en el siglo XXI como herramientas para impulsar las diversas estrategias mercadológicas. A pesar de que la década de los 80 en el siglo XX se caracterizó por el surgimiento de la red Internet y la década de los 90 atestiguó el surgimiento de los gigantes Amazon, Yahoo y Google, el siglo XXI ha sido el escenario para que la red social de Facebook se haya abierto a la interacción general de personas, empresas, instituciones gubernamentales y ha atraído el desarrollo de la era de la web 2.0.

A partir de ahí, el nacimiento de plataformas tecnológicas y de comunicación a través de videoconferencias o videollamadas como Zoom, Meet, Skype y otras que se encuentran transformando el mercado, no sólo para la industria turística sino para todos las acciones humanas en términos económicos, sociales, políticos, culturales, entre otras.

\section{Discusión}

La actividad en el turismo se ha tornado compleja y constante en la globalidad, ante la cual surgen nuevas necesidades y expectativas de servicio. Así, la innovación y aplicación de tecnologías de información y comunicación para el desarrollo e implementación de la promoción turística con un plan de mercadotecnia con un diseño que integre a todos los grupos sociales y gubernamentales en un contexto de responsabilidad frente al medio ambiente, se convierte en un campo emergente de investigación, ya que para Cavazos (2016):

- Debe tener como propósito proveer a través del ecosistema 
tecnológico mejores procesos y sistemas para el desarrollo del turismo, su interoperabilidad y sinergias.

- Requiere de mayor creatividad metodológica por parte de los investigadores, $\mathrm{y} \cdot$ Que

- obliga a un mayor esfuerzo interdisciplinario para entender a profundidad las necesidades de los consumidores y la dinámica de las interfaces entre turismo y tecnología, a fin de ayudar a integrar los enfoques hacia la maximización del valor generado por todos los actores involucrados.

De los resultados que arrojaron las encuestas aplicadas a un sector representado por jóvenes entre los 18 y los 25 años de edad, que son usuarios frecuentes de las redes sociales, es posible identificar que de una muestra de 150 jóvenes, el 98 \% afirmó conocer diferentes redes sociales como Facebook, Twitter, Instagram, Tinder y, lo más reciente, Whatsapp, atribuyéndoles de manera general el atributo "como medios de comunicación efectiva".

De los 150 encuestados, el $78 \%$ de los jóvenes (no hay distinción entre mujeres y hombres) manifiesta ser usuario de plataformas y aplicaciones tecnológicas para adquisición de productos - alimentos, compra de artículos específicos como ropa, juegos de video, bisutería o cosméticos y accesorios-o solicitud de servicios como transportación terrestre UBER o precompra de boletos para ingresar a eventos, conciertos, cine, entre otros.

Otro uso manifestado por este mismo porcentaje de los encuestados habla del uso de las redes sociales para realizar preguntas (como preguntarle todo a Google, páginas de Alguien Sabe $i$ ? y las redes sociales para conectarse con amigos y conocidos para una información personalizada. Un porcentaje de $48 \%$ de jóvenes manifestaron utilizar las redes sociales como espacio de entretenimiento - uso de juegos en línea- o para aprender con el uso de videos publicados en la red YouTube.

Acorde a sus edades, el $55 \%$ de las respuestas indican que su promedio de uso de las redes es de 4 a 6 horas por día, disminuyendo su uso si ubican información estática, publicidad oficial, ventas directas.

Finalmente, cuando se pregunta por el uso de las redes sociales en el turismo, el 90\% manifiesta haber consultado páginas web de hoteles, hostales, búsqueda de ofertas en transportación terrestre y aérea, así como para ubicar opciones de arrendamiento de casas o cabañas para uso grupal en fines de semana.

\section{Conclusiones}

A lo largo de los puntos desarrollados en este trabajo se ha podido percibir la importancia del turismo para la comunidad receptora y la disminución que este ha sufrido por causa de la Pandemia COVID-19, el cual por estudios realizados a nivel mundial no acaban de descifrar las 
características claras de este nuevo virus ni cómo combatirlo, sin embargo lo que si resulta cierto es que nos enfrentaremos a una nueva normalidad, todo un cambio de paradigma que implica más que adaptarnos a una vestimenta, cuidados higiénicos, etc. representa un cambio de cultura y conciencia donde todos aprendamos a respetar el derecho a vivir de los demás.

De acuerdo también a lo vertido es un hecho que el turismo deberá ser visto de otra manera, donde quienes viajan no solo lo harán eligiendo la comodidad, atractivos y precios de un hotel sino aquel que ofrezca la seguridad de que no se van a enfermar, llevando a las empresas del sector turístico a tomar medidas que deben ir más allá de ofrecer un buen servicio o recibirlo con una sonrisa.

De acuerdo con las estimaciones recogidas en el sector privado, la recuperación de ninguna manera se concretaría en 2020 y podría alcanzar en el mes de diciembre un 55\% en el mercado doméstico y $46 \%$ en el mercado internacional, sobre el nivel observado en 2019. Se estima una pérdida del $27 \%$ del empleo turístico, es decir, poco más de un millón de personas podrían perder su empleo derivado de la contingencia.

El reto para la mercadotecnia turística utilizando las herramientas digitales, enfrentará las difíciles condiciones para un mercado muy golpeado por las condiciones sanitarias y el distanciamiento social, como amenazas del entorno. Sin embargo, también se encontrará con un turista cada vez más más exigente, quien tiene al alcance de su teléfono inteligente o dispositivo móvil, una gran cantidad de información para comparar productos y servicios y tomar la mejor decisión de acuerdo a sus condiciones personales, familiares o con sus grupos sociales; es un usuario al que no le incomoda hacer pública su opinión, manifestando lo positivo o negativo de su experiencia como turista y tiene las competencias digitales y las herramientas para comunicar sus experiencias de forma inmediata. Será necesario continuar investigando sobre el potencial de Internet y las Redes Sociales para incrementar la competitividad y la promoción del país, sus programas, patrimonio, atractivos, riquezas naturales y capital humano.

\section{References:}

1. Arias, F. (2012). El Proyecto de Investigación. Introducción a la Metodología Científica. Caracas, Venezuela: Editorial EPISTEME, C.A.

2. Arechavala, L. (2020). Presentación de resultados del Modelo para el Fortalecimiento y Desarrollo de Innovación Tecnológico-Empresarial del Estado de Hidalgo. Fumec México Estados Unidos y CITNOVA Hidalgo. México.

3. Barroso, GM. (2010). Marketing turístico internacional. La marca Brasil. Estudios y Perspectivas en Turismo $\mathrm{N}^{\circ} 19$. Buenos Aires, 
Argentina.

Recuperado

de https://www.redalyc.org/pdf/1807/180713901005.pdf

4. Cavazos, J. (2016). Avances y retos para el marketing turístico en la era de la web 2.0. en Examen de Tendencias del Turismo en el Umbral del siglo XXI. UABC-UACJ-UdG. México.

5. Conferencia Nacional de Gobernadores, \& Consejo Nacional Empresaria Turístico (2020). Alianza Emergente para el Turismo. Recuperado de file:///C:/Users/Noemi/Desktop/Journal\%20Hidalgo/PRESENTACIO $\% \mathrm{CC} \% 81 \mathrm{~N} \% 20$ ANETUR\%20\%20-\%20CONAGO\%20$\% 20 \mathrm{CNET} \% 20-\% 20230620$.pdf

6. DOF (2020). Acuerdo por el que se expide la Estrategia Nacional de Pueblos Mágicos. Diario Oficial de la Federación. $1^{\circ}$ de octubre de 2020. México.

7. Espino, L. \& Pérez-Nazar, L. (2020). Presentación de Proyecto: Diseño, Desarrollo e Integración de Prototipo de un Consultor Virtual Personal de Negocios con Integración de Big Data, CITNOVA Hidalgo, México.

8. Gobierno de México, Secretaría de Salud, \& Secretaría de Turismo (2020). Gobierno de México. Recuperado de https://coronavirus.gob.mx/wpcontent/uploads/2020/05/Lineamiento_nacional_reapertura_turismo_ 20052020.pdf

9. Gobierno de México (2020). Semáforo COVID-19. Recuperado de https://coronavirus.gob.mx/semaforo/

10. Hernández Sampieri , R., Fernández Collado, C. \& Baptista Lucio, P. (2004). Metodología de la Investigación. México: McGraw-Hill Interamericana.

11. Hernandéz, E. (2020). Crearán Alianza Emergente para rescatar al turismo de Hidalgo. Milenio 2020, pág. 1.

12. Hidalgo, G. D. (2020). Lineamientos Generales Sanitarios para el retorno exitoso en la reapertura de establecimientos con base al nivel de riesgo por el virus SARS-CoV2 (COVID-19) en el Estado de Hidalgo. Recuperado de http://mineraldelmonte.hidalgo.gob.mx/descargables/Info_General/Se maforizacionReaperturaHidalgo.pdf

13. INEGI (2020). INEGI. Recuperado de https://www.inegi.org.mx/app/cuadroentidad/Hgo/2019/21/21_3

14. Knoepfel, P., Corinne, L., Varone, F., \& Hinojosa, M. (2007). Hacia un modelo de análisis de políticas públicas operativo. Un enfoque basado en los actores, sus recursos y las instituciones. Ciencia Política, (3), pp. 6-29. 
15. México, D. D. (2020). Anuario de Morbilidad 1984 -2019. Recuperado de http://www.epidemiologia.salud.gob.mx/anuario/html/glosario.html

16. México, G. D. (2019). Subsecretaria de Prevención y Proimoción de la Salud.

Recuperado de https://www.gob.mx/cms/uploads/attachment/file/546237/Comunicad o_Tecnico_Diario_COVID-19_2020.04.12.pdf

17. Municipal, P. (2020). Presidencia Municipal 2016-2020 Pachuca. Recuperado de HYPERLINK "https://datos.pachuca.gob.mx/comunicacion_social/boletines/boletin 862.php" https://datos.pachuca.gob.mx/comunicacion_social/boletines/boletin8 62.php

18. OMT (2020). Barometro OMT. Obtenido de https://www.unwto.org/es/taxonomy/term/347

19. Reyes, A. (2020). En Hidalgo cinco mil empresas turísticas han cerrado temporalmente por el covid-19. Milenio 2020, pág. 1.

20. Reyes, A. (2020). Sanción, arrastre y corralón para quienes incumplan medidas de reducción vehicular. Milenio 2020, pág. 4.

21. Salud, O. M. (2020). Organizacción Mundial de la Salud. Recuperado de HYPERLINK "https://www.who.int/es/health-topics/coronavirus" https://www.who.int/es/health-topics/coronavirus

22. Salud, O. M. (2020). Ornanización Mundial de la Salud. Recuperado de https://www.who.int/es/dg/speeches/detail/who-director-general-sopening-remarks-at-the-media-briefing-on-covid-19---10-april-2020

23. Salud, S. D. (2020). Gobierno de México. Recuperado de https://www.gob.mx/cms/uploads/attachment/file/541582/Comunicad o_Tecnico_Diario_COVID-19_2020.03.16.pdf

24. Selltiz, C. (1980). Métodos de investigación en la relaciones sociales. Madrid: Rialp. 